American Journal of Applied Sciences 6 (12): 2060-2065, 2009

ISSN 1546-9239

(C) 2009 Science Publications

\title{
Lot-Sizing Decisions under Trade Credit Depending on the Ordering Quantity in Fuzzy Annual Demand
}

\author{
Chui-Yu Chiu, Zhi-Ping Lin and Yi Lin \\ Department of Industrial Engineering and Management, \\ National Taipei University of Technology, No.1, Sec. 3, Chung-Shiao E. Rd., Taipei, Taiwan, ROC
}

\begin{abstract}
Problem statement: In reality, there are of various products such as liquids, volatile, medicines and materials, in which the rate of deterioration is very large. However, little attention has been mentioned what the effects of deterioration occur in most inventory systems. Also, the loss of the deterioration should not be neglected as an important issue. Approach: In this study, we proposed the problem of determining the Economic Order Quantity (EOQ) for exponentially deteriorating items under the conditions of permissible delay in payments. Recent researches revealed that the payment for the product must be made forthwith when the order quantity is less than the allowable delay in payments. The fixed trade credit period was permitted, or else. Therefore, we utilized the fuzzy theory to implement more considerable answers via numerical examples which were provided to illustrate the results clearly at the end of study. Results: This study discussed the optimal replenishment cycle time for an exponentially deteriorating product under conditions of permissible delay in payments to take the order quantity into account. Conclusion/Recommendations: This study presented another fuzzy environment inventory model which accounts for the permissible delay in payments offered by supplier to the retailer. From the results, it can be concluded that another point of view to decision makers in uncertainty.
\end{abstract}

Key words: Permissible delay in payments, fuzzy inventory model, deterioration, order quantity

\section{INTRODUCTION}

There are of various products such as liquids, volatile, medicines and materials, in which the rate of deterioration is very large. However, most inventory systems are implicit assumption without considering the effects of deterioration and, the loss due to deterioration should not be neglected. In this study, we assume that items have the exponential distribution for the time to deterioration.

To stimulate output, suppliers are often willing to extended payment privileges to retailers which are quite prevalent in some industries nowadays. Such credit policies may be applied as an alternative to price discounts to induce larger orders. It is indicated that ${ }^{[1-4]}$, such policies are not thought to provoke competitors to reduce their prices and thus introduce lasting price reductions.

Practically, a few of pharmaceutical companies and agricultural machinery manufacturers offer a larger credit period for larger amount of purchase rather than giving some discount on unit price.
Moreover, there are two categories, presented by Khouja and Mehrez ${ }^{[5]}$, investigated the effect of supplier credit policies: (1) one is that credit terms are independent of the order quantity and (2) the other is that credit terms are linked to the order quantity. In the further case, suppliers always use favorable credit terms to encourage customers for higher ordering quantities. In other words, the favorable credit terms apply only at large order quantities and are used in place of quantity discounts. In this study, we fully focus on the latter case.

The retailer has to decide whether it is worth to alter the regular ordering pattern to exploit other opportunities. As a result, this study incorporates both Hwang and Shinn and Khouja and Mehrez ${ }^{[3,5]}$. In addition, the basic decision problem for the retailer can be modeled as the design of the cost-minimizing ordering strategies. The model incorporates the fuzziness of annual demand that use Yao and $\mathrm{Wu} \mathrm{s}^{\left[{ }^{[6]}\right.}$ ranking method for fuzzy number to defuzzy and then illustrate the solution procedure of the proposed algorithm to find the corresponding optimal solution.

Corresponding Author: Chui-Yu Chiu, Department of Industrial Engineering and Management,

National Taipei University of Technology, No.1, Sec. 3, Chung-Shiao E. Rd., Taipei, Taiwan, ROC 
Am. J. Applied Sci., 6 (12): 2060-2065, 2009

\section{MATERIALS AND METHODS}

$$
\begin{aligned}
& \mathrm{W}^{*}=\frac{1}{\lambda} \ln \left(\frac{\lambda}{\tilde{\mathrm{D}}} \overline{\mathrm{W}}+1\right) \\
& \tilde{\mathrm{P}}_{1}(\mathrm{~T})=\frac{\mathrm{S}}{\mathrm{T}}+\frac{\mathrm{c} \tilde{\mathrm{D}}\left(\mathrm{e}^{\lambda \mathrm{T}}-1\right)}{\lambda \mathrm{T}}+\frac{\tilde{\mathrm{D}}(\mathrm{H}+\mathrm{cR})\left(\mathrm{e}^{\lambda \mathrm{T}}-\lambda \mathrm{T}-1\right)}{\lambda^{2} \mathrm{~T}}
\end{aligned}
$$

if $\mathrm{T}>0$

$$
\tilde{\mathrm{P}}_{2}(\mathrm{~T})=\frac{\mathrm{S}}{\mathrm{T}}+\frac{\mathrm{c} \tilde{\mathrm{D}}\left(\mathrm{e}^{\lambda \mathrm{T}}-1\right)}{\lambda \mathrm{T}}+\frac{\mathrm{H} \tilde{\mathrm{D}}\left(\mathrm{e}^{\lambda \mathrm{T}}-\lambda \mathrm{T}-1\right)}{\lambda^{2} \mathrm{~T}}+\frac{\mathrm{cI} \tilde{\mathrm{D} T}}{2}-\mathrm{cID} \mathrm{M}
$$

if $\mathrm{T}>0$

$$
\begin{aligned}
\tilde{\mathrm{P}}_{3}(\mathrm{~T}) & =\frac{\mathrm{S}}{\mathrm{T}}+\frac{\mathrm{c} \tilde{\mathrm{D}}\left(\mathrm{e}^{\lambda \mathrm{T}}-1\right)}{\lambda \mathrm{T}}+\frac{\mathrm{H} \tilde{\mathrm{D}}\left(\mathrm{e}^{\lambda \mathrm{T}}-\lambda \mathrm{T}-1\right)}{\lambda^{2} \mathrm{~T}} \\
& +\frac{\mathrm{cR} \tilde{\mathrm{D}}\left(\mathrm{e}^{\lambda(\mathrm{T}-\mathrm{M})}-\lambda(\mathrm{T}-\mathrm{M})-1\right)}{\lambda^{2} \mathrm{~T}}-\frac{\mathrm{cIN} \mathrm{M}^{2}}{2 \mathrm{~T}}
\end{aligned}
$$

if $\mathrm{T}>0$

$\mathrm{P}=$ The total variable cost function per unit time when:

$$
M>W^{*}=\quad M>W^{*}=\left\{\begin{array}{l}
\tilde{\mathrm{P}}_{1}(\mathrm{~T}) \text { if } 0<\mathrm{T}<\mathrm{W}^{*} \\
\tilde{\mathrm{P}}_{2}(\mathrm{~T}) \text { ifW } \\
\tilde{\mathrm{P}}_{3}(\mathrm{~T}) \mathrm{T}<\mathrm{M} M \mathrm{M}
\end{array}\right.
$$

$\mathrm{P}=$ The total variable cost function per unit time when:

$$
\mathrm{M} \leq \mathrm{W}^{*}=\left\{\begin{array}{l}
\tilde{\mathrm{P}}_{1}(\mathrm{~T}) \text { if } 0<\mathrm{T}<\mathrm{W} \\
\tilde{\mathrm{P}}_{3}(\mathrm{~T}) \text { ifW } \\
* \mathrm{~T}
\end{array}\right.
$$

$\mathrm{T}^{*}$ : The optimal replenishment cycle time of $\tilde{\mathrm{P}}(\mathrm{T})$.

\section{Assumptions:}

- Replenishments are instantaneous with a known and constant lead time

- No shortages are allowed

- The inventory system involves only one item

- The supplier proposes a certain credit period and sales revenue generated during the credit period is deposited in an interest-bearing account with rate I. At the end of the period, the credit is settled and the retailer starts paying the capital opportunity cost for the items in stock with rate $R(R \geq 1)$

- Inventory is depleted not only by demand but also by deterioration. Deterioration follows an exponential distribution with parameter. (From Ghare and Schrader, the deterioration rate is a constant fraction of the on-hand inventory.)

- If $\mathrm{Q}<\overline{\mathrm{W}}$, the delay in payments is not permitted. Otherwise, certain 0xed trade credit period $\mathrm{M}$ is permitted

- We consider the problem with fuzzy annual demand by fuzzifying $D$ to a triangular fuzzy number $\tilde{\mathrm{D}}$, where $\tilde{\mathrm{D}}=\left(\mathrm{D}-\Delta_{1}, \mathrm{D}, \mathrm{D}-\Delta_{2}\right), 0<\Delta_{1}<\mathrm{D}$, $0<\Delta_{2}$ and $\Delta_{1}, \Delta_{2}$ are both determined by decisionmakers.

\section{RESULTS}

Two numerical examples which provide more detailed information are presented in this part.

Example 1: Let $\mathrm{S}=\$ 200 /$ order, $\mathrm{h}=\$ 5 /$ unit/year, $\mathrm{R}=\$ 0.15 / \$$ year, $\mathrm{I}=\$ 0.12 / \$ /$ year, $\lambda=0.01$ and $\mathrm{M}$ $=0.3$ year be used when $\mathrm{M}>\mathrm{W}^{*}$.

Example 2: Let $\mathrm{S}=\$ 200 /$ order, $\mathrm{h}=\$ 5 /$ unit/year, $\mathrm{R}=\$ 0.15 /$ /year, $\mathrm{I}=\$ 0.12 /$ /year, $\lambda=0.01$ and $\mathrm{M}=0.1$ year be used when $\mathrm{M} \leq \mathrm{W}^{*}$.

The number marked with " $*$ " is the optimal solution in crisp sense. Then, the relative variation between fuzzy case and crisp case for the quantity at which the delay in payments is permitted and the optimal replenishment cycle time can be measured respectively as follows:

$$
\begin{aligned}
& \operatorname{Re} 1 \mathrm{~W}=\left[\frac{\mathrm{W}_{\mathrm{f}}-\mathrm{W}_{\mathrm{c}}^{*}}{\mathrm{~W}_{\mathrm{c}}^{*}}\right] \times 100 \% \\
& \operatorname{Re} 1 \mathrm{P}=\left\{\frac{\mathrm{P}\left(\mathrm{W}_{\mathrm{f}}\right)-\mathrm{P}\left(\mathrm{W}_{\mathrm{c}}^{*}\right)}{\mathrm{P}\left(\mathrm{W}_{\mathrm{c}}^{*}\right)}\right\} \times 100 \%
\end{aligned}
$$

The results of the example 1 and 2 are shown in Table 1 and 2.

\section{DISCUSSION}

Fuzzy annual demand inventory model with ordering quantity in safety factor considerations Decision rule of the optimal order cycle time when $\mathrm{M}>\mathrm{W}^{*}$. Consider the following equations:

$$
\begin{aligned}
& \mathrm{P}_{1}{ }^{\prime}(\mathrm{T})=0 \text { if } \mathrm{T}>0 \\
& \mathrm{P}_{2}{ }^{\prime}(\mathrm{T})=0 \text { if } \mathrm{T}>0 \\
& \mathrm{P}_{3}{ }^{\prime}(\mathrm{T})=0 \text { if } \mathrm{T} \geq \mathrm{M}
\end{aligned}
$$


Am. J. Applied Sci., 6 (12): 2060-2065, 2009

Table 1: The results of example 1

\begin{tabular}{|c|c|c|c|c|c|c|c|c|c|c|}
\hline W & A1 & $\mathrm{A} 2$ & $\mathrm{~d}\left(\tilde{\mathrm{D}}, \tilde{0}_{1}\right)$ & $\mathrm{W}^{*}$ & $\mathrm{P}^{*}$ & $\Delta_{1}$ & $\Delta_{2}$ & $\Delta_{3}$ & Rel W (\%) & Rel P (\%) \\
\hline \multirow[t]{6}{*}{500} & 50 & 50 & 3000.0 & 0.1670 & 207163 & $>0$ & $>0$ & $>0$ & 0.00 & 0.000 \\
\hline & 100 & 50 & 3012.5 & 0.1658 & 208012 & $>0$ & $>0$ & $>0$ & -0.72 & 0.410 \\
\hline & 90 & 60 & 3007.5 & 0.1661 & 207673 & $>0$ & $>0$ & $>0$ & -0.54 & 0.250 \\
\hline & 80 & 70 & 3002.5 & 0.1663 & 207333 & $>0$ & $>0$ & $>0$ & -0.42 & 0.082 \\
\hline & 70 & 80 & 2997.5 & 0.1666 & 206994 & $>0$ & $>0$ & $>0$ & -0.24 & -0.080 \\
\hline & 60 & 90 & 2992.5 & 0.1669 & 206654 & $>0$ & $>0$ & $>0$ & -0.06 & -0.250 \\
\hline \multirow[t]{6}{*}{90} & 50 & 50 & 300.0 & 0.2990 & 21545 & $>0$ & $<0$ & $<0$ & 0.00 & 0.000 \\
\hline & 100 & 50 & 312.5 & 0.2876 & 22416 & $>0$ & $<0$ & $<0$ & -3.81 & 4.000 \\
\hline & 90 & 60 & 307.5 & 0.2922 & 22068 & $>0$ & $<0$ & $<0$ & -2.32 & 2.400 \\
\hline & 80 & 70 & 302.5 & 0.2971 & 21719 & $>0$ & $<0$ & $<0$ & -0.64 & 0.800 \\
\hline & 70 & 80 & 297.5 & 0.3021 & 21371 & $>0$ & $<0$ & $<0$ & 1.00 & -0.810 \\
\hline & 60 & 90 & 292.5 & 0.3072 & 21022 & $>0$ & $<0$ & $<0$ & 3.00 & -2.400 \\
\hline
\end{tabular}

Table 2: The results of example 2

\begin{tabular}{|c|c|c|c|c|c|c|c|c|c|}
\hline W & A1 & $\mathrm{A} 2$ & $\mathrm{~d}\left(\tilde{\mathrm{D}}, \tilde{0}_{1}\right)$ & $\mathrm{W}^{*}$ & $\mathrm{P}^{*}$ & $\Delta_{1}$ & $\Delta_{4}$ & Rel W (\%) & $\operatorname{Rel} \mathrm{P}(\%)$ \\
\hline \multirow[t]{6}{*}{500} & 50 & 50 & 1200.0 & 0.4158 & 86790 & $>0$ & $>0$ & 0.00 & 0.00 \\
\hline & 100 & 50 & 1212.5 & 0.4115 & 87679 & $>0$ & $>0$ & -1.00 & 1.00 \\
\hline & 90 & 60 & 1207.5 & 0.4132 & 87323 & $>0$ & $>0$ & -0.63 & 0.60 \\
\hline & 80 & 70 & 1202.5 & 0.4150 & 86967 & $>0$ & $>0$ & -0.20 & 0.20 \\
\hline & 70 & 80 & 1197.5 & 0.4166 & 86612 & $>0$ & $>0$ & 0.10 & -0.20 \\
\hline & 60 & 90 & 1192.5 & 0.4184 & 86256 & $>0$ & $>0$ & 0.60 & -0.62 \\
\hline \multirow[t]{6}{*}{160} & 50 & 50 & 1000.0 & 0.1599 & 71562 & $>0$ & $<0$ & 0.00 & 0.00 \\
\hline & 100 & 50 & 1012.5 & 0.1579 & 72421 & $>0$ & $<0$ & -1.20 & 1.20 \\
\hline & 90 & 60 & 1007.5 & 0.1587 & 72077 & $>0$ & $<0$ & -0.75 & 0.70 \\
\hline & 80 & 70 & 1002.5 & 0.1595 & 71733 & $>0$ & $<0$ & -0.25 & 0.23 \\
\hline & 70 & 80 & 997.5 & 0.1603 & 71390 & $>0$ & $<0$ & 0.25 & -0.20 \\
\hline & 60 & 90 & 992.5 & 0.1611 & 71046 & $>0$ & $<0$ & 0.75 & -0.72 \\
\hline
\end{tabular}

If the respective roots of 1-3 exist, then they are unique. Let $\mathrm{T}_{1} *$ denote the root of Eq. 1 and let $\mathrm{T}_{2}{ }^{*}$ denote the root of Eq. 2. On the other hand, let $\mathrm{T}_{3} *$ denote the root of Eq. 3. By the convexity of Pi (T) $(i=1,2,3)$, we have:

$$
\begin{gathered}
\tilde{\mathrm{P}}_{1}^{\prime}(\mathrm{T}) \begin{cases}<0 \text { if } \mathrm{T}<\mathrm{T}_{1} * & \text { (a) } \\
=0 \text { ifT }=\mathrm{T}_{1} * & \text { (b) } \\
>0 \text { ifT }>\mathrm{T}_{1} * & \text { (c) }\end{cases} \\
\tilde{\mathrm{P}}_{2}^{\prime}(\mathrm{T}) \begin{cases}<0 \mathrm{ifT}<\mathrm{T}_{2}^{*} & \text { (a) } \\
=0 \mathrm{ifT}=\mathrm{T}_{2} * & \text { (b) } \\
>0 \text { ifT }>\mathrm{T}_{2} * & \text { (c) }\end{cases}
\end{gathered}
$$

$$
\tilde{\mathrm{P}}_{3}^{\prime}(\mathrm{T}) \begin{cases}<0 \text { ifM } \leq \mathrm{T}<\mathrm{T}_{3} * & \text { (a) } \\ =0 \text { if } \mathrm{T}=\mathrm{T}_{3} * & \text { (b) } \\ >0 \text { if } \mathrm{T}>\mathrm{T}_{3} * & \text { (c) }\end{cases}
$$

Equation 4, 5 and 6a-c imply that $\operatorname{Pi}(\mathrm{T})$ is decreasing on $\left(0, \mathrm{Ti}^{*}\right)$ and increasing on $\left(\mathrm{Ti}^{*}, \infty\right)$ for all $\mathrm{i}=1,2,3$. About the existence of $\mathrm{Ti}^{*}(\mathrm{i}=1$ and 2$)$, since $\lim \rightarrow 0+\mathrm{Pi}^{\prime}(\mathrm{T})=-\infty$ and $\operatorname{limT} \rightarrow \infty \mathrm{Pi}^{\prime}(\mathrm{T})=\infty$, the intermediate value theorem implies that $\mathrm{Ti}^{*}$ exists for $\mathrm{i}=1$ and 2 . On the other hand, since $\operatorname{limT} \rightarrow \infty$ $\mathrm{P} 3^{\prime}(\mathrm{T})=\infty$, there are two cases to occur:

- If $\mathrm{P}_{3}{ }^{\prime}(\mathrm{M}) \leq 0$, then $\mathrm{T}_{3}{ }^{*}$ exists
- If $\mathrm{P}_{3}{ }^{\prime}(\mathrm{M})>0$, we cannot make sure whether $\lim _{\mathrm{T} \rightarrow 0}{ }^{+}$ $\mathrm{P}_{3}{ }^{\prime}(\mathrm{T})$ is less than 0 . Therefore, we do not know whether $\mathrm{T}_{3}{ }^{*}$ exists. Although it is so, the convexity of $\mathrm{P}_{3}(\mathrm{~T})$ on $[\mathrm{M}, \infty)$ implies that $\mathrm{P}_{3}(\mathrm{~T})$ is increasing on $[\mathrm{M}, \infty)$ if $\mathrm{P}_{3}{ }^{\prime}(\mathrm{M})>0$ :

$$
\begin{aligned}
\mathrm{P}_{1}^{\prime}\left(\mathrm{W}^{*}\right)=- & \frac{\mathrm{S}}{\mathrm{W}^{* 2}}+\frac{\tilde{\mathrm{D}}(\mathrm{H}+\lambda \mathrm{c}+\mathrm{cR})\left(\lambda \mathrm{W} * \mathrm{e}^{\lambda \mathrm{W}^{*}}-\mathrm{e}^{\lambda \mathrm{W} *}+1\right)}{\lambda^{2} \mathrm{~W}^{2}} \\
\mathrm{P}_{2}^{\prime}\left(\mathrm{W}^{*}\right)= & -\frac{\mathrm{S}}{\mathrm{W}^{* 2}}+\frac{\tilde{\mathrm{D}}(\mathrm{H}+\lambda \mathrm{c})\left(\lambda \mathrm{W} * \mathrm{e}^{\lambda \mathrm{W}^{*}}-\mathrm{e}^{\lambda \mathrm{W}^{*}}+1\right)}{\lambda^{2} \mathrm{~W}^{* 2}} \\
& +\frac{\mathrm{cII}}{2}
\end{aligned}
$$

Furthermore, we set:

$$
\begin{aligned}
& \Delta_{1}=-\frac{\mathrm{S}}{\mathrm{W} *^{2}}+\frac{\tilde{\mathrm{D}}(\mathrm{H}+\lambda \mathrm{c}+\mathrm{cR})\left(\lambda \mathrm{W} * \mathrm{e}^{\lambda \mathrm{W}^{*}}-\mathrm{e}^{\lambda \mathrm{W} *}+1\right)}{\lambda^{2} \mathrm{~W} *^{2}} \\
& \Delta_{2}=-\frac{\mathrm{S}}{\mathrm{W}^{* 2}}+\frac{\tilde{\mathrm{D}}(\mathrm{H}+\lambda \mathrm{c})\left(\lambda \mathrm{W} * \mathrm{e}^{\lambda \mathrm{W}^{*}}-\mathrm{e}^{\lambda \mathrm{W}^{*}}+1\right)}{\lambda^{2} \mathrm{~W}^{* 2}}+\frac{\mathrm{cII} \tilde{\mathrm{D}}}{2} \\
& \Delta_{3}=-\frac{\mathrm{S}}{\mathrm{M}^{* 2}}+\frac{\tilde{\mathrm{D}}(\mathrm{H}+\lambda \mathrm{c})\left(\lambda \mathrm{W} * \mathrm{e}^{\lambda \mathrm{W}^{*}}-\mathrm{e}^{\lambda \mathrm{W}^{*}}+1\right)}{\lambda^{2} \mathrm{~W}^{* 2}}+\frac{\mathrm{cII}}{2}
\end{aligned}
$$

\section{Theorem 1:}

- If $\Delta_{1}>0, \Delta_{2} \geq 0$ and $\Delta_{3}>0$, then $\mathrm{P}\left(\mathrm{T}^{*}\right)=$ $\min \left\{\mathrm{P}\left(\mathrm{T}_{1}{ }^{*}\right), \mathrm{P}\left(\mathrm{W}^{*}\right)\right\}$ 

cost:

Hence $\mathrm{T}^{*}$ is $\mathrm{T}_{1}{ }^{*}$ or $\mathrm{W}^{*}$ associated with the least

- If $\Delta_{1}>0, \Delta_{2}<0$ and $\Delta_{3}>0$, then $\mathrm{P}\left(\mathrm{T}^{*}\right)=\mathrm{P}\left(\mathrm{T}_{2}{ }^{*}\right)$. Hence $\mathrm{T}^{*}$ is $\mathrm{T}_{2}{ }^{*}$

- If $\Delta_{1}>0, \Delta_{2}<0$ and $\Delta_{3} \leq 0$, then $\mathrm{P}\left(\mathrm{T}^{*}\right)=\mathrm{P}\left(\mathrm{T}_{3}{ }^{*}\right)$. Hence $\mathrm{T}^{*}$ is $\mathrm{T}_{3}{ }^{*}$

- If $\Delta_{1} \leq 0, \Delta_{2}<0$ and $\Delta_{3}>0$, then $\mathrm{P}\left(\mathrm{T}^{*}\right)=\mathrm{P}\left(\mathrm{T}_{2}{ }^{*}\right)$. Hence $\mathrm{T}^{*}$ is $\mathrm{T}_{2}^{*}$

- If $\Delta_{1} \leq 0, \Delta_{2}<0$ and $\Delta_{3} \leq 0$, then $\mathrm{P}\left(\mathrm{T}^{*}\right)=\mathrm{P}\left(\mathrm{T}_{3}{ }^{*}\right)$. Hence $\mathrm{T}^{*}$ is $\mathrm{T}_{3}^{*}$

Decision rule of the optimal order cycle time when $\mathrm{M} \leq \mathrm{W}^{*}$.

$\mathrm{P}(\mathrm{T})$ can be expressed as follows:

$\mathrm{P}(\mathrm{T})=\left\{\begin{array}{l}\mathrm{P}_{1}(\mathrm{~T}) \text { if } 0<\mathrm{T}<\mathrm{W}^{*} \\ \mathrm{P}_{3}(\mathrm{~T}) \text { if } \mathrm{W}^{*} \leq \mathrm{T}\end{array}\right.$

$$
\begin{aligned}
\mathrm{P}_{3}^{\prime}\left(\mathrm{W}^{*}\right)= & -\frac{\mathrm{S}}{\mathrm{W} *^{2}}+\frac{\tilde{\mathrm{D}}(\mathrm{H}+\lambda \mathrm{c})\left(\lambda \mathrm{W} * \mathrm{e}^{\lambda \mathrm{W}^{*}}-\mathrm{e}^{\lambda \mathrm{W}^{*}}+1\right)}{\lambda^{2} \mathrm{~W}^{* 2}} \\
& +\frac{\mathrm{cID} \mathrm{D}^{2}}{2 \mathrm{~W}^{2}}+\frac{\mathrm{cR} \tilde{\mathrm{D}}\left(\lambda \mathrm{W} * \mathrm{e}^{\lambda\left(\mathrm{W}^{*}-\mathrm{M}\right)}-\mathrm{e}^{\lambda\left(\mathrm{W}^{*}-\mathrm{M}\right)}-\lambda \mathrm{M}+1\right)}{\lambda^{2} \mathrm{~W}^{* 2}}
\end{aligned}
$$

We let:

$$
\begin{aligned}
\Delta_{4}= & -\frac{\mathrm{S}}{\mathrm{W}^{* 2}}+\frac{\tilde{\mathrm{D}}(\mathrm{H}+\lambda \mathrm{c})\left(\lambda \mathrm{W} * \mathrm{e}^{\lambda \mathrm{W}^{*}}-\mathrm{e}^{\lambda \mathrm{W} *}+1\right)}{\lambda^{2} \mathrm{~W} *^{2}} \\
& +\frac{\mathrm{cID} \mathrm{M}^{2}}{2 \mathrm{~W} *^{2}}+\frac{\mathrm{cR} \tilde{\mathrm{D}}\left(\lambda \mathrm{W} * \mathrm{e}^{\lambda(\mathrm{W} *-\mathrm{M})}-\mathrm{e}^{\lambda(\mathrm{W} *-\mathrm{M})}-\lambda \mathrm{M}+1\right)}{\lambda^{2} \mathrm{~W}^{* 2}}
\end{aligned}
$$

\section{Theorem 2:}

- If $\Delta_{1}>0$ and $\Delta_{4} \geq 0$, then $\operatorname{TVC}\left(\mathrm{T}^{*}\right)=\min \left\{\operatorname{TVC}\left(\mathrm{T}_{1}^{*}\right)\right.$, TVC $\left.\left(\mathrm{W}^{*}\right)\right\}$. Hence $\mathrm{T}^{*}$ is $\mathrm{T}_{1}{ }^{*}$ or $\mathrm{W}^{*}$ associated with the least cost

- If $\Delta_{1}>0$ and $\Delta_{4}<0$, then $\operatorname{TVC}\left(\mathrm{T}^{*}\right)=\min \left\{\mathrm{TVC}\left(\mathrm{T}_{1}{ }^{*}\right)\right.$, $\left.\operatorname{TVC}\left(\mathrm{T}_{3}{ }^{*}\right)\right\}$. Hence $\mathrm{T}^{*}$ is $\mathrm{T}_{1}{ }^{*}$ or $\mathrm{T}_{3}{ }^{*}$ associated with the least cost

- If $\Delta_{1} \leq 0$ and $\Delta_{4}<0$, then $\operatorname{TVC}\left(\mathrm{T}^{*}\right)=\operatorname{TVC}\left(\mathrm{T}_{3}{ }^{*}\right)$. Hence $\mathrm{T}^{*}$ is $\mathrm{T}_{3}{ }^{*}$

where, $d\left(\tilde{D}, \tilde{0}_{1}\right)$, the signed distance of fuzzy number $\tilde{D}$ to $\tilde{0}_{1}$, by Definition 1 , is $\mathrm{d}\left(\tilde{\mathrm{D}}, \tilde{0}_{1}\right)=\mathrm{D}+\frac{1}{4}\left(\Delta_{2}-\Delta_{1}\right)$.

The following algorithm can be used to find the optimal values of the quantity at which the delay in payments is permitted replenishment cycle time and optimal order quantity.

Step 1: Obtain A1 and 2 from the decision-maker
Step 2: If $M \leq W^{*}$, then go to Step 4. Otherwise, go to Step 3: Step 3

- If $\Delta_{1}>0, \Delta_{2} \geq 0$ and $\Delta_{3}>0$, then $\mathrm{T}^{*}$ is $\mathrm{T}_{1} *$ or $\mathrm{W}^{*}$ associated with the least cost:

- If $\Delta_{1}>0, \Delta_{2}<0$ and $\Delta_{3}>0$, then $\mathrm{T}^{*}$ is $\mathrm{T}_{2}{ }^{*}$

- If $\Delta_{1}>0, \Delta_{2}<0$ and $\Delta_{3} \leq 0$, then $\mathrm{T}^{*}$ is $\mathrm{T}_{3} *$

- If $\Delta_{1} \leq 0, \Delta_{2}<0$ and $\Delta_{3}>0$, then $\mathrm{T}^{*}$ is $\mathrm{T}_{2}{ }^{*}$

- If $\Delta_{1} \leq 0, \Delta_{2}<0$ and $\Delta_{3} \leq 0$, then $\mathrm{T}^{*}$ is $\mathrm{T}_{3}{ }^{*}$

Step 4:

- If $\Delta_{1}>0$ and $\Delta_{4} \geq 0$, then $\mathrm{T}^{*}$ is $\mathrm{T}_{1} *$ or $\mathrm{W}^{*}$ associated with the least cost

- If $\Delta_{1}>0$ and $\Delta_{4}<0$, then $\mathrm{T}^{*}$ is $\mathrm{T}_{1} *$ or $\mathrm{T}_{3} *$ associated with the least cost

- If $\Delta_{1} \leq 0$ and $\Delta_{4}<0$, then $\mathrm{T}^{*}$ is $\mathrm{T}_{3} *$

According to the convexity of $\mathrm{P}_{\mathrm{i}}(\mathrm{T})(\mathrm{i}=1,2,3)$, the Newton's method can be used to locate $\mathrm{T}_{\mathrm{i}}{ }^{*}$ for all $\mathrm{i}=1,2,3$.

This study discusses the optimal replenishment cycle time for an exponentially deteriorating product under conditions of permissible delay in payments to take the order quantity into account. If $\mathrm{Q}<\overline{\mathrm{W}}$, the delay in payment is not permitted ${ }^{[7]}$. Or else, the fixed trade period $\mathrm{M}$ is permitted. There are two cases (i) $\mathrm{M}>\mathrm{W}^{*}$ and (ii) $\mathrm{M} \leq \mathrm{W}^{*}$ to be explored. Theorem 1 gives the solution procedure to find $\mathrm{T}^{*}$ when $\mathrm{M}>\mathrm{W}^{*}$. Theorem 2 gives the solution procedure to find $\mathrm{T}^{*}$ when $\mathrm{M} \leq \mathrm{W}^{*}$. Numerical examples are given to illustrate Theorem 1 and 2 and the effect of the inventory deteriorating rate on the optimal cost and the replenishment time. Furthermore, an algorithm to find the optimal replenishment cycle time is presented. The proposed algorithm indicates that $\mathrm{T}^{*}$ can be one of $\mathrm{T}_{1}{ }^{*}$, $\mathrm{T}_{2}{ }^{*}, \mathrm{~T}_{3} *$ and $\mathrm{W}^{*}$. According to the convexity of $\mathrm{TVC}_{\mathrm{i}}(\mathrm{T})(\mathrm{i}=1,2,3)$, the Newton's method can be used to locate $\mathrm{T}_{\mathrm{i}} *$ for all $\mathrm{i}=1,2,3$. Finally, if $\overline{\mathrm{W}}=0$, from the viewpoint of the cost, Hwang and Shinn ${ }^{[3]}$ can be treated as a special case of this study. When the deterioration is ignored, Eq. 4 a-c and $6 a$ and $b$ are reduced to Khouja and Mehrez ${ }^{[5]}$.

The part of Fuzzy, please see the results in Fig. 1-4.

Definition: For any $\mathrm{a}$ and $0 \in \mathrm{R}$, define the signed distance (Kaufmann and Gupta, Zimmermann, Yao and $\mathrm{Wu}$ ) from a to 0 as $\mathrm{d}_{0}(\mathrm{a}, 0)=\mathrm{a}$. If $\mathrm{a}>0$, $\mathrm{a}$ is on the right hand side of origin 0 and the distance from a to 0 is $\mathrm{d}_{0}(\mathrm{a}, 0)=\mathrm{a}$. If $\mathrm{a}<0, \mathrm{a}$ is on the left hand side of origin 0 and the distance from a to 0 is $-d_{0}(a, 0)=-a$. This is the reason why $d_{0}(a, 0)=a$ is called the signed distance from a to $0^{[6,8,9]}$. 


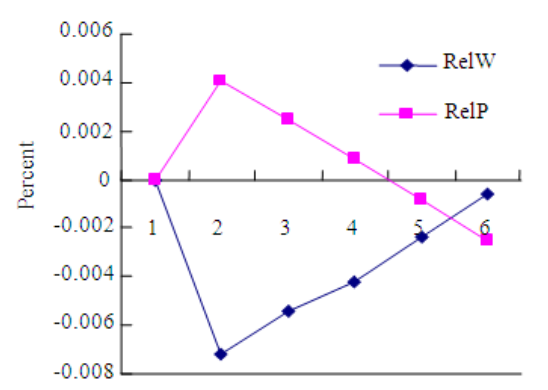

Fig. 1: Example $1 \mathrm{~W}=500$

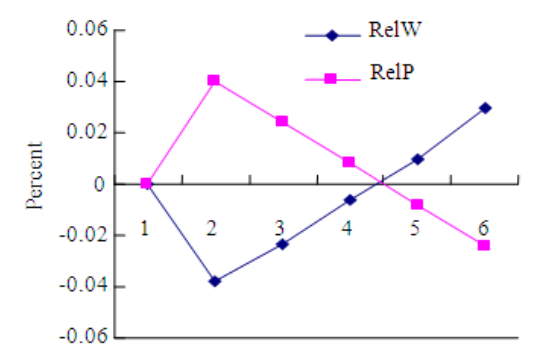

Fig. 2: Example $2 \mathrm{~W}=500$

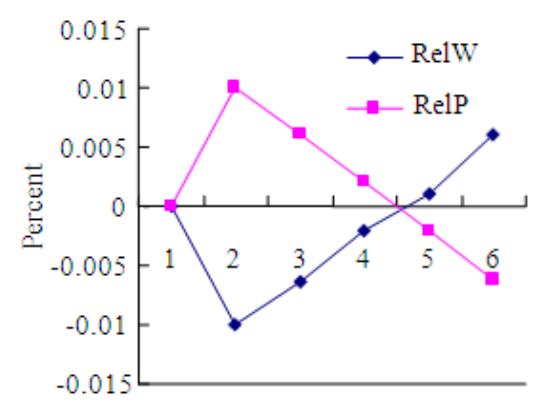

Fig. 3: Example $2 \mathrm{~W}=160$

Let $\Omega$ be the family of all fuzzy sets $\tilde{A}$ defined on $\mathrm{R}$, the $\alpha$-cut of $\tilde{\mathrm{A}}$ is $\mathrm{A}(\alpha)=\left[\mathrm{A}_{\mathrm{L}}(\alpha), \mathrm{A}_{\mathrm{U}}(\alpha)\right], 0 \leqq \alpha \leqq \cdot 1$ and both $A_{L}(\alpha)$ and $A_{U}(\alpha)$ are continuous functions on $\alpha \in[0,1]$. Then, for any $\tilde{A} \in \Omega$, we have:

$$
\tilde{\mathrm{A}}=\bigcup_{0 \leq \alpha \leq 1}\left[\mathrm{~A}_{\mathrm{L}}(\alpha)_{\alpha}, \mathrm{A}_{\mathrm{U}}(\alpha)_{\alpha}\right]
$$

Besides, for every $\alpha \in[0,1]$, the $\alpha$-level fuzzy interval $\left[\mathrm{A}_{\mathrm{L}}(\alpha) \alpha, \mathrm{A}_{\mathrm{U}}(\alpha) \alpha\right]$ has a one-to-one correspondence with the crisp interval $\left[\mathrm{A}_{\mathrm{L}}(\alpha), \mathrm{A}_{U}(\alpha)\right]$, that is, $\left[A_{L}(\alpha) \alpha, A_{U}(\alpha) \alpha\right] \leftrightarrow\left[A_{L}(\alpha), A_{U}(\alpha)\right]$ is one-to-one mapping.

The signed distance of two end points, $\mathrm{A}_{\mathrm{L}}(\alpha)$ and $\mathrm{A}_{\mathrm{U}}(\alpha)$ to 0 are $\mathrm{d}_{0}\left(\mathrm{~A}_{\mathrm{L}}(\alpha), 0\right)=\mathrm{A}_{\mathrm{L}}(\alpha)$ and $\mathrm{d}_{0}\left(\mathrm{~A}_{\mathrm{U}}(\alpha), 0\right)=$ $\mathrm{A}_{\mathrm{U}}(\alpha)$.
Hence, the signed distance of interval $\left[\mathrm{A}_{\mathrm{L}}(\alpha)\right.$, $A_{U}(\alpha)$ ] to 0 can be represented by their average $\frac{\left(A_{L}(\alpha)+A_{u}(\alpha)\right)}{2}$. Therefore, the signed distance of interval $\left[A_{L}(\alpha), A_{U}(\alpha)\right]$ to 0 can be represented as:

$$
\begin{aligned}
& \mathrm{d}_{0}\left(\left[\left(\mathrm{~A}_{\mathrm{L}}(\alpha), \mathrm{A}_{\mathrm{u}}(\alpha)\right)\right], 0\right) \\
& =\left[\frac{\mathrm{d}_{0}\left(\mathrm{~A}_{\mathrm{L}}(\alpha), 0\right)+\mathrm{d}_{0}\left(\mathrm{~A}_{\mathrm{u}}(\alpha), 0\right)}{2}\right]=\frac{\left(\mathrm{A}_{\mathrm{L}}(\alpha)+\mathrm{A}_{\mathrm{u}}(\alpha)\right)}{2}
\end{aligned}
$$

Further, because of the 1-level fuzzy point $\tilde{0}_{1}$, is mapping to the real number 0 , the signed distance of $\left[A_{L}(\alpha) \alpha, A_{U}(\alpha) \alpha\right]$ to $\tilde{0}_{1}$, can be defined as:

$$
\begin{aligned}
& \mathrm{d}\left(\left[\mathrm{A}_{\mathrm{L}}(\alpha)_{\alpha}, \mathrm{A}_{\mathrm{u}}(\alpha)_{\alpha}\right], \tilde{0}_{1}\right) \\
& =\mathrm{d}_{0}\left(\left[\mathrm{~A}_{\mathrm{L}}(\alpha), \mathrm{A}_{\mathrm{u}}(\alpha)\right], 0\right)=\frac{\left(\mathrm{A}_{\mathrm{L}}(\alpha)+\mathrm{A}_{\mathrm{u}}(\alpha)\right)}{2}
\end{aligned}
$$

Thus, since the above function is continuous on $0 \leqq \alpha \leqq 1$ for $\tilde{A} \in \Omega$, we can use the following equation to define the signed distance of $\tilde{A}$ to $\tilde{0}_{1}$, as follows.

\section{CONCLUSION}

Fundamentally, in this study, we suggest another fuzzy environment inventory model which accounts for the permissible delay in payments offered by the supplier to the retailer, is mainly focused on uncertain environment.

The contributions of this study and the approach we take to solve the problem are significant because:

- This study brings attention to the trade credit that is of major importance in the operations of enterprises in many economics and which depends on the order quantity that has been left out of studies in inventory theory that deal with quantity discounts

- The focus on permissible delay in payments depending on the ordering quantity, that is, besides stimulates the much needed research in this area; it provides a useful model for many organizations that use the decision rule to improve their total operating cost in reality

- It is clear from this study that the retailer can assess their monetary impact to find the optimal ordering policy under realistic conditions linking marketing as well as operations management concerns 
Finally, future research in this direction should also incorporate more real-world cases, more supply chain stages or echelons considerations and attempt to more refined solution methodologies.

\section{REFERENCE}

1. Arcelus, F.J. and G. Srinivasan, 1993. Delay of payments for extraordinary purchases. J. Operat. Res. $\quad$ Soc., 44: 785-795. http://cat.inist.fr $/$ ?aModele $=$ afficheN\&cpsidt $=4850$ 250

2. Chu, P., K.J. Chung and S.P. Lan, 1998. Economic order quantity of deteriorating items under permissible delay in payments. Comput. Operat. Res., 25: 817-824. DOI: $10.1016 /$ S03050548(98)00006-9.

3. Hwang, H. and S.W. Shinn, 1997. Retailer's pricing and lot sizing policy for exponentially deteriorating products under the condition of permissible delay in payments. Comput. Operat. Res., 24: 539-547. DOI: 10.1016/S03050548(96)00069-X

4. Shinn, S.W., 1997. Determining optimal retail price and lot size under day-terms supplier credit. Comput. Ind. Eng., 33: 717-720. DOI: 10.1016/S0360-8352(97)00230-1

5. Khouja, M. and A. Mehrez, 1996. Optimal inventory policy under different supplier credits policies. J. Manufat. Syst., 15: 334-339. DOI: 10.1016/0278-6125(96)84196-3

6. Yao, J.S. and K. Wu, 2000. Ranking fuzzy numbers based on decomposition principle and signed distance. Fuzzy Sets Syst., 116: 275-288. DOI: 10.1016/S0165-0114(98)00122-5
7. Chung, K.J., S.K. Goyal and Y.F. Huang, 2005. The optimal inventory policies under permissible delay in payments depending on the ordering quantity. Int. J. Prod. Econ., 95: 203-213. DOI: 10.1016/j.ijpe.2003.12.006

8. Kaufmann, A., B. Esposito and M.M. Gupta 1991. Introduction to Fuzzy Arithmetic: Theory and Applications. Van Nostrand Reinhold Company, New York, ISBN: 10: 0442008996, pp: 384.

9. Zimmermann, H.J., 1996. Fuzzy Set Theory-and its Application. 3rd Edn., Kluwer Academic Publishers, Norwell, MA., ISBN: 0-7923-9624-3, pp: 435. 